\title{
Design of Reinforced Concrete Water Reservoirs
}

\author{
Oguzhan Ates (Corresponding author) \\ Faculty of Engineering and Architecture, Department of Civil Engineering, \\ Yozgat Bozok University, Yozgat, Turkey \\ E-mail: ates127@yahoo.com \\ Ziyafeddin Babayev \\ Faculty of Engineering and Architecture, Department of Civil Engineering, \\ Yozgat Bozok University, Yozgat, Turkey \\ E-mail: ziyafeddin.babayev@bozok.edu.tr
}

\begin{abstract}
In this study, these reservoirs will be developed by the Çorum Provincial Administration. Thanks to these reservoirs to be developed, it is aimed to get water from the new water tank with a capacity of 20 tons with the submersible pump which will run about $5 \mathrm{~m}$ vertical. The structure of the building under water and ground effects will be dimensioned by reinforced concrete curtain elements. The damage caused by pumps, which will complete the service life in a short time by working horizontally, will be prevented. In addition, the efficiency of submersible pumps not reduced to 5 meters depth will be increased. The thesis study was carried out in two stages. The first one involves the examination of the Project being implemented. In the second stage, the newly designed warehouse was evaluated. The results will be compared with the current application. The gap in these issues will be tried to be filled in the literature.
\end{abstract}

Keywords: Storage tanks, Watertanks, Reinforced concrete wall, Pump pumping stations, Submersible pumps.

DOI: $10.7176 /$ JSTR/6-07-01

\section{Betonarme Su Biriktirme Haznelerinin Tasarımı}

\section{Giriş}

$\mathrm{Su}$; insanların ve diğer canlıların hayatlarını sürdürebilmeleri için en temel ihtiyaçlarından biridir. Bu nedenle insanlık tarihi boyunca hayatın merkezinde yer almıştır. Geçmişte yerleşim yerleri suların kenarlarında oluşturulmuştur. Su kaynakları için savaş planları hazırlanarak toplumlar birbirleriyle savaşmışlardır. Bu durum günümüzde de güncelliğini korumaktadır. Bu sebeple insanlar geçmişten beri kullanacakları suyu depolama ihtiyacı duymuşlardır. Özellikle yerleşik hayata geçen toplumların suya olan bağımlılığı artmıştır. Bu bağımlılıkla birlikte su ihtiyacı miktar olarak ta artmıştır. Artan su ihtiyacı suyun daha güvenli depolanmasını gerektirmiştir [1]. Toplumların gelişmişliği ihtiyaçlarını karşılayabilecekleri temiz ve yeterli suyun bulunmasıyla doğrudan ilişkilidir. Toplumlar geliştikçe ihtiyaç duyulan suyun temini büyük önem kazanmıştır. Günümüzde toplumların nüfusu günden güne artarken, ihtiyaçları karşılamak için kullanılan kaynaklar azalmaktadır. Kaynakların bir kısmı artan ihtiyaçları karşılamak üzere tüketilmektedir. Bir kısmı da gerekli tedbirler alınmadığı için kirlenmekte ve kullanılamaz hale gelmektedir. Bu durum tatlı su kaynă̆ rezervlerinin kritik seviyeye düşmesine sebep olmuştur. Konutlarda, tarım alanlarında ve sanayi tesislerinde kullanılan su miktarı gün geçtikçe artmaktadir [2].

Geçmişte suyu depolamak için kayalar oyulmuş, derelerin önüne setler çekilmiş ve ahşaptan oluklar yapılmıştır. Fakat zamanla teknolojinin gelişmesine bağlı olarak, çelik ve betonarmeden su depoları yapılmaya başlanmıştır. Günümüzde bu depolara ek olarak ön gerilmeli betonarme depolarda inşa edilmektedir [3].

Genel olarak günümüzde sıvı tutucu hazneler (depolar); içme ve kullanma sularının, kullanılmış sıvıların, kara, deniz ve hava araçlarının kullandığı akaryakıtların ve sanayi de kullanılan sıvıların depolanmasında kullanılmaktadır. Nüfus artışıyla paralel olarak ihtiyaç duyulan sıvı tutucu haznelerin (depoların) boyut ve sayıları da artmaktadır [4].

Hazne kapasitesi belirleme aşaması, su kaynaklarını geliştirmede önemli bir problemi oluşturmakta olup ihtiyaç debisine ve suyun kullanım amacına bağlıdır. Suların depolandığı hazneler büyük ve küçük olmak

1 I $\mathrm{P}$ a g e

www.iiste.org 
üzere ikiye ayrılır. Büyük hazneler baraj, gölet vb.dir. Küçük hazneler ise içme suyu depoları, biriktirme hazneleri (depoları) vb.dir [5].

Ülkemizde birçok küçük yerleşim yerinde temiz kullanılabilir su ihtiyacının karşılanabilmesi için alt yapı çalışmalarına ihtiyaç duyulmaktadır. Bu nedenle az nüfuslu bölgeler için yapılacak az tonajlı biriktirme hazneleri önem kazanmaktadır. Çorum'un köylerinde hane sayısına bağlı olarak genellikle 30, 50 ve 100 ton su kapasiteli içme suyu hazneleri Çorum İl Özel İdaresi tarafindan yaptırılmaktadır. Bu haznelerde önemli olan hidrolik, yapısal ve geçirimsizlik özellikleridir.

Hidrolik açıdan bir içme suyu deposunda amaç, kaynaktan cazibe ya da terfi ile iletilen suyun debisi ile şebekeye verilen debi arasında dengeleme yapmaktır. Bu dengeleme sayesinde su alma, tasfiye ve pompa tesisleri ile iletim hattının ortalama debiye göre boyutlandırılması sağlanmış olmaktadır. Ayrıca depo yerinin kotu, köyün en son evinin 15-20 m üzerinde olmalıdır. Depo hacmi ise ilgili köy nüfusu, günlük su tüketimi ve yangın durumuna göre belirlenir. Yapısal açıdan depolar, insanların kullanımı için gerekli olan su miktarı ile sanayi tesisleri ve enerji üretimi için gerekli olan sıvıların biriktirilmesinde kullanılan yapılar olarak tanımlanabilir $[5,6]$.

Gömme ya da ayaklı olmakla beraber; dikdörtgen, kare ya da silindirik olabilir. Ülkemizde iller bankası veya başka kuruluşlar tarafından üretilen çok sayıda ve tipte içme suyu depo projesi bulunmaktadır.

Geçirimsizlik içme suyu depolarında çok önemlidir. Normal betonarme yapılarda kabul edilebilen çatlaklar bu yapılarda kabul edilemez. Geçirimsizliğin sağlanması amacıyla Çorum İl Özel İdaresince 5 $\mathrm{mm}$ kalınlıkta hdpe levhalarla su yalıtımı uygulaması yaptırılmaktadır. Ayrıca sürme esaslı malzemelerle de yalıtım yapılmaktadır.

$\mathrm{Bu}$ özelliklerin dışında depolar gerekli bütün mekanik ve elektriksel donanım ile donatılır. Ayrıca biriktirme depoları (hazneleri) dediğimiz (bu makalenin de konusu olan) motor odaları altında bulunan depolarda mevcuttur. Bu depolarda amaç, suyun ana içme suyu deposuna pompa gücü ile iletilmesidir. (Ayrıntılı bilgi için bkz. Oğuzhan Ateş, 2019)

\section{Materyal ve Metod}

$\mathrm{Bu}$ çalı̧̧manın esas amacı az nüfuslu bölgeler için yapılacak içme suyu biriktirme haznelerinin hacmini artırarak hazne içine yerleştirilen dalgıç pompanın daha derinden su alabilmesini sağlayacak betonarme yapının tasarımını hazırlamaktır.

Araştırmada, mevcut biriktirme haznelerinin durumunun değerlendirilebilmesi amacıyla elde edilen veriler Çorum İl Özel İdaresinden ve yazarın kendi şahsi envanterinden elde edilmiştir. Yeni biriktirme haznesi ise bilgisayar paket programları kullanılarak, TS500 (2000) ve 2007 deprem yönetmeliğine uygun olarak hazırlanmıştır.

\section{Bulgular ve Araştırma}

3.1. Dalgıç pompalar ve biriktirme haznelerinin değerlendirilmesi

Dalgıç pompaların boyları yaklaşı 1 ile $4 \mathrm{~m}$ arasında değişmektedir. Güçleri arttıkça boyları da artmaktadır. Bu pompalar emiş yaptıkları seviyenin üstündeki suyu basabilirler. Bu seviyenin altındaki suyu basamazlar. Örneğin hâlihazırda Çorum İl Özel İdaresinde kullanılan biriktirme binalarında, motopomplar 2,5 m derinliğinde dik bir konumda yerleştirilirler. Bu durumda, biriktirme haznesinin toplam hacmini 20 ton kabul edersek motopomp bunun 10 tonluk kısmını basmaktadır. Diğer 10 tonluk kısım sürekli depoda kalmaktadır. $\mathrm{Bu}$ durumun ortadan kaldırılarak, 20 ton suyun tamamının basılabilmesi için, motopompun emiş yaptığı noktanın daha derinde olması gerekir. Bunun içinde 2 yol vardır. Birincisi pompayı yatay konumda, daha derine yerleştirmektir. Ancak bu durum motopompun verimi ve sağlıklı çalışması açısından istenen bir durum değildir. Çünkü motopomplar dik konumda çalıştırılmaya uygun üretilirler. Yatay konumda çalışınca fanları zorlanır ve sık arıza verirler.

Bu şekilde Çorum İl Özel İdaresince bazı yerleşim yerlerinde uygulama yapılmış, ancak zaman içerisinde çok sık arızalarla karşılaşıııışıtı. Bu nedenle bu birinci yoldan vazgeçilmiştir.

Ayrıca motopompun sağlıklı ve verimli çalışması açısından devreye girdikten sonra uzun süre çalışmas gerekir. Sürekli dur kalk yapması arızalara sebebiyet verir ve kalkma anında yüksek akım çektiğinden elektrik faturası daha yüksek olur. Örnek olarak motopomp, 20 ton suyu 1 saatte basarsa 10 tonluk suyu 30 dakikada basar. Bu da hâlihazırda Çorum İl Özel İdaresince kullanılan biriktirme haznelerinde, dik konulan motopompların, çok sık dur kalk yaptığı anlamına gelir ve istenilen bir durum değildir.

İkinci yol ise, bu çalışmada yeni tasarımı yapılmış olan daha derin biriktirme hazneleridir. Bu çalışmayla, yeni tasarımı yapılan biriktirme haznelerinde, motopomp dik olarak yerleştirildikten sonra, emiş yaptığ 1 seviyenin üstünde eski tasarıma göre yaklaşık 2 kat fazla su olacaktır. Yani dalgıç pompalar çalışmaya başladıktan sonra örneğin 4 yerine 8 saat sonra duracaktır. Bu da motopompun verimi ve sık arızaların engellenmesi açısından uygun olacaktır (Ateş, 2019).

2| P a g e www.iiste.org 


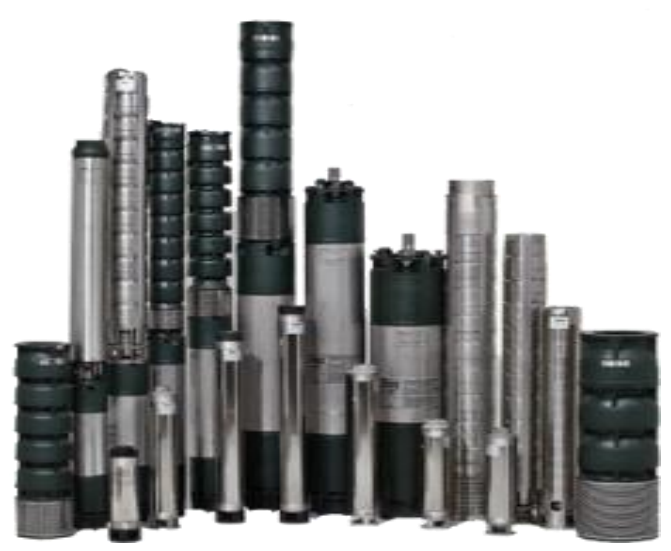

Şekil 1: Çeşitli Ebatlarda Dalgıç Pompalar [7]

3.2. Mevcut biriktirme haznesi kesiti

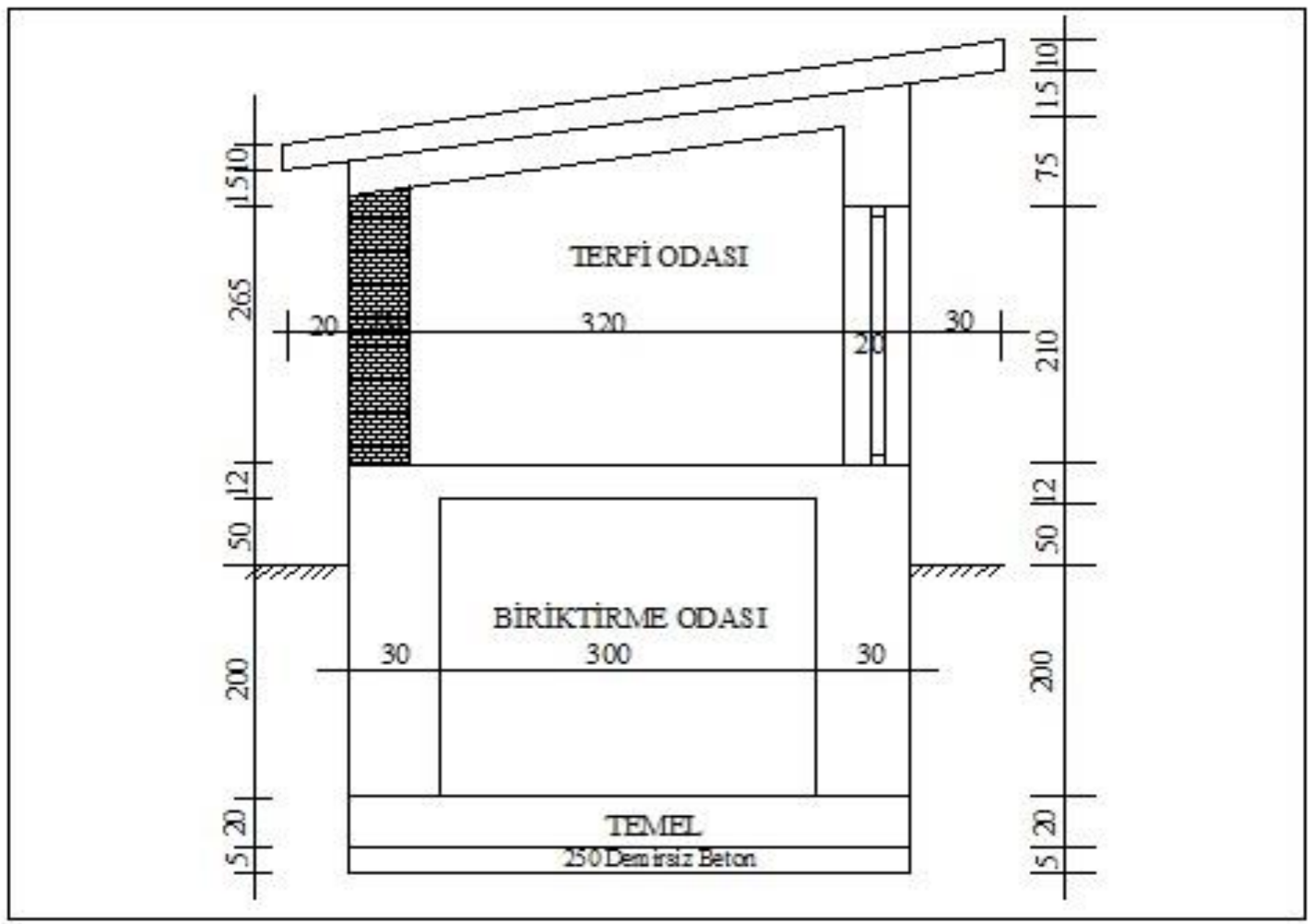

Şekil 2: Terfi Binası Kesiti 


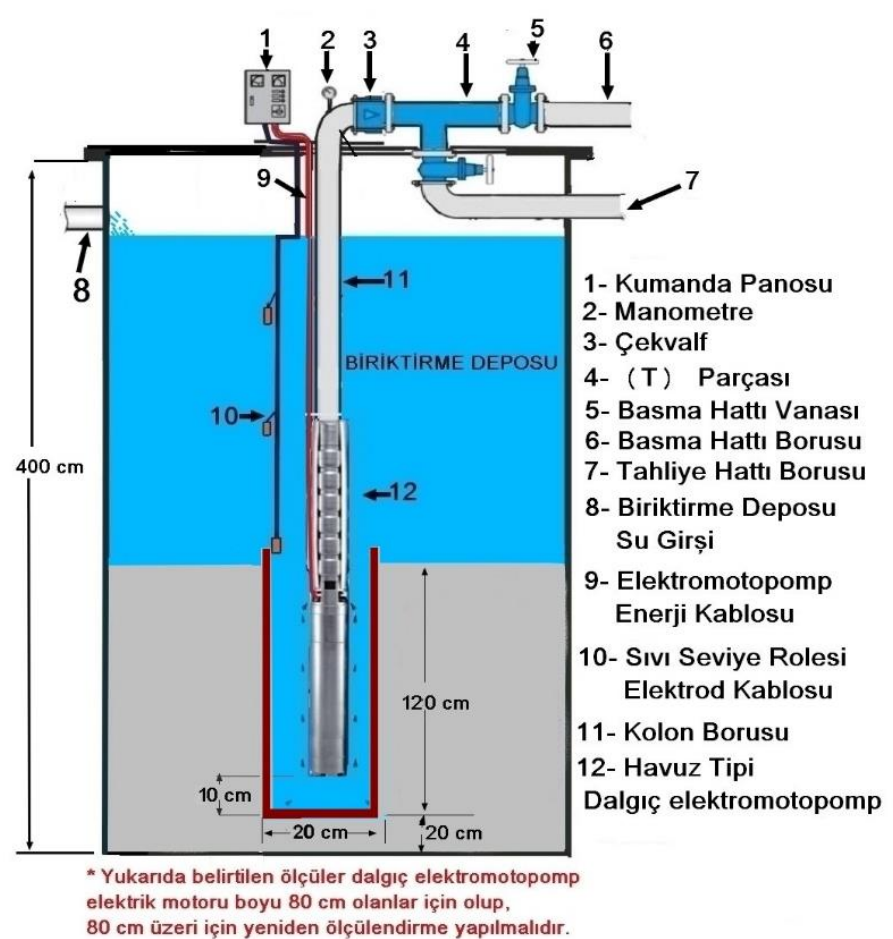

Şekil 3: Dalgıç Elektromotopomp Biriktirme Haznesi Montaj Şeması [8]

3.3. Yeni biriktirme haznesi kesiti ve proje parametreleri

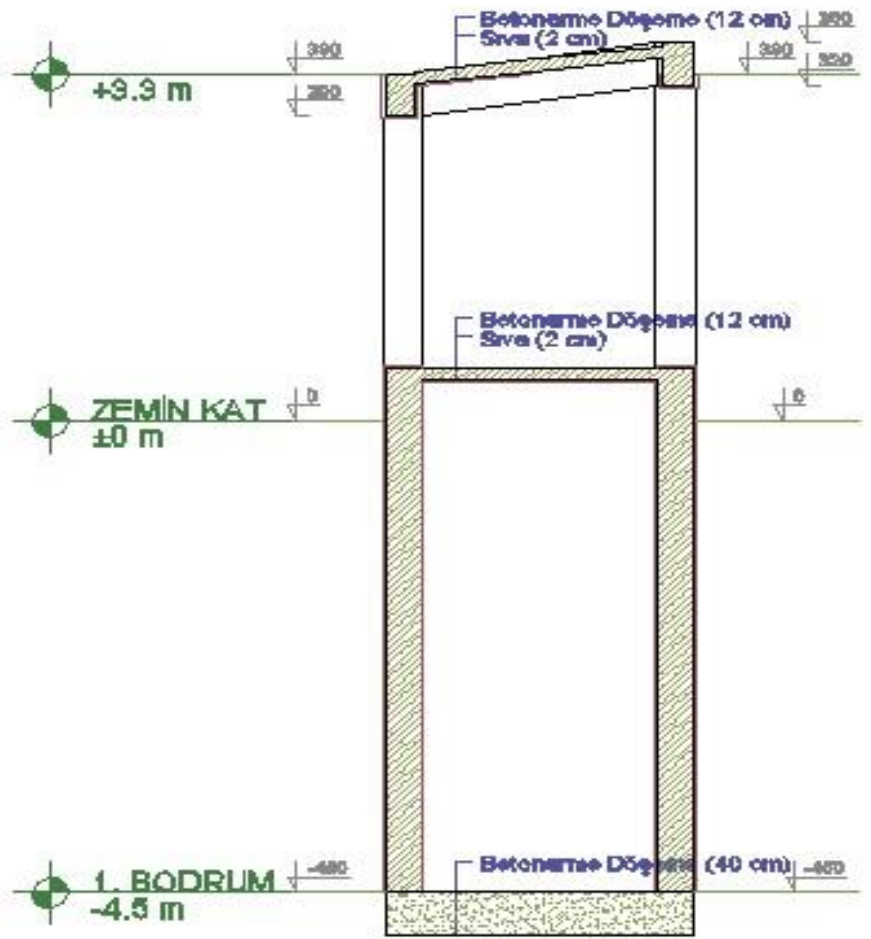

Şekil 4: Yeni Biriktirme Haznesi Kesiti (Ateş, 2019) 
Tablo 1: Proje Hesapları İçin Kullanılan Parametreler

\begin{tabular}{|c|c|}
\hline \multicolumn{2}{|l|}{ MALZEME PARAMETRELERI } \\
\hline Beton Sinifi & Donatı Çeliği \\
\hline $\mathrm{C} 25$ & S420 \\
\hline \multicolumn{2}{|l|}{ ZEMIN PARAMETRELERI } \\
\hline Yerel Zemin Sinifi & Yerel Zemin Grubu \\
\hline Z4 & D \\
\hline Zemin Emniyet Gerilmesi & Zemin Yatak Katsayısı \\
\hline Zem $=1.1 \mathrm{kgf} / \mathrm{cm}^{2}$ & $\mathrm{~K}=1000 \mathrm{tf} / \mathrm{m}^{3}$ \\
\hline \multicolumn{2}{|l|}{ DEPREM PARAMETRELERI } \\
\hline Bina Önem Katsayısı & Etkin Yer Ivmesi Katsayısı \\
\hline$I=1.0$ & $\mathrm{~A}_{0}=0.30$ \\
\hline Yapı Davranıș Katsayısı & Hareketli Yük Azaltma Katsayısı \\
\hline$R x=6.8 \quad R y=6.8$ & $n=0.30$ \\
\hline
\end{tabular}

\section{Sonuçlar}

4.1 Su Sicaklığg ve Hava Durumunun Değerlendirilmesi

Sicaklık biyolojik aktiviteyi artırır. Sıcaklığın artmasıyla suda oluşan reaksiyonların hızları artar ve sudaki çözünmüş oksijen (ÇO) miktarı azalır. Bu da olumsuz bir durum oluşturur. Ayrıca katı maddelerin suda çökelme ve ayrışma hızları da sıcaklıkla değişiklik gösterir. Mesela, su sıcaklığının artması oksijenin suda çözünmesini azaltır. Balıkların ise oksijen ihtiyacını artırır. Kısacası yüksek sıcaklık birçok kimyasal bileşiğin çözünürlüğünü arttırarak, kirleticilerin su içindeki canlı hayatı üstündeki etkilerini çoğaltır. [9]. Biriktirme hazneleri ya da kuyulardaki su sıcaklığı maksimum $30{ }^{\circ} \mathrm{C}$ olmalıdır. Kış aylarında suyun buz tuttuğu zamanlarda pompalar kullanılmamalıdır.

\subsection{Betonarme ve Mimari Açıdan Sonuçlar}

Hâlihazırda Çorum İl Özel İdaresince kullanılan projenin maliyeti ile yeni tasarımı yapılan projenin maliyetleri incelendiğinde aşağıda belirtilen başlıklardaki farklar tespit edilmiştir.

1-KAZI VE DOLGU: Yeni tasarlanan biriktirme haznesi için kazı derinliği artırıldığından dolayı $75 \mathrm{~m}^{3}$ daha fazla kazı ve $67,12 \mathrm{~m}^{3}$ daha fazla dolgu yapılması gerekmektedir. Eski tasarım için $50 \mathrm{~m}^{3} \mathrm{kaz}$ gerekirken, yeni tasarımda $125 \mathrm{~m}^{3}$ olmaktadır. Eski tasarım için 24,08 $\mathrm{m}^{3}$ dolgu gerekirken, yeni tasarımda 91,20 $\mathrm{m}^{3}$ olmaktadır. Yeni tasarım biriktirme haznesi için daha fazla makineli çalışma gerekmektedir.

2-BETON: Yeni tasarlanan biriktirme haznesinin eni ve boyu azaltıldığından dolayı $0,62 \mathrm{~m}^{3}$ daha az grobeton gerekmektedir. Eski tasarım için $1,30 \mathrm{~m}^{3}$ grobeton gerekirken, yeni tasarımda $0,68 \mathrm{~m}^{3}$ yeterlidir. Ancak toprak seviyesi altı perde beton yüksekliği artırıldığından, eski tasarımda $16,49 \mathrm{~m}^{3}$ beton gerekirken, yeni tasarımda bu rakam $21,26 \mathrm{~m}^{3}$ olmaktadır. Yeni tasarım biriktirme haznesi için $4,77 \mathrm{~m}^{3}$ daha fazla beton gerekmektedir.

3-KALIP: Yeni tasarlanan biriktirme haznesinin perde beton yüksekliği eskiye göre daha fazla olduğundan, 35,86 $\mathrm{m}^{2}$ ahşap kalıp miktarı artmıştır. Eski tasarımda 103,19 $\mathrm{m}^{2}$ ahşap kalıp, yeni tasarımda $139,05 \mathrm{~m}^{2}$ gerekmektedir.

4-SU YALITIMI: HDPE levhalarla ya da sürme esaslı yalıtım malzemeleri ile yapılabilir. Her iki tasarımda da yaklaşık aynı miktarda yalıtım malzemesi gerekmektedir. Eski tasarım $39 \mathrm{~m}^{2}$, yeni tasarım ise $38,88 \mathrm{~m}^{21}$ dir.

5-YAĞLI BOYA: Her iki tasarımda da kapı ve pencere boyutları aynı olduğundan aynı miktarda yağlı boya yapılmaktadır. Eski ve yeni tasarım $39 \mathrm{~m}^{2}$, yeni tasarım ise $38,88 \mathrm{~m}^{2}$ dir.

6-DEMIR: Eski tasarımda sadece 0,88 ton ince demir kullanılmaktadır. Yeni tasarımda ise 0,84 ton ince demir, 1,49 ton'da kalın demir kullanılmaktadır. Demir miktarı toplamda 1,45 ton artmıştır.

7-KALIP İSKELESİ: Eski tasarıma göre 52,20 $\mathrm{m}^{3}$ kalıp iskelesi gerekmekte iken, yeni tasarıma göre

5 I P a g e

www.iiste.org 
29,24 $\mathrm{m}^{3}$ yeterli olmaktadır. Kalıp iskelesi 22,96 $\mathrm{m}^{3}$ azalmıştır.

8-SIVA VE BOYA: Eski hazne için $84,62 \mathrm{~m}^{2}$ sıva ve boya gerekirken, yeni hazne için $49,87 \mathrm{~m}^{2}$ gerekmektedir. Miktar 34,75 $\mathrm{m}^{2}$ azalmıştır.

9-KATRAN BADANA: Eski tasarımda 37,73 $\mathrm{m}^{2}$ olan imalat miktarı $3,87 \mathrm{~m}^{2}$ artarak 41,60 $\mathrm{m}^{2}$ olmuştur.

10-ŞAP: İmalat miktarı 9,11 $\mathrm{m}^{2}$ azalmıştır.

11-TUĞLA DUVAR: Eski tasarımın en ve boy ölçüleri daha büyük olduğundan örülecek duvar miktarı $33,83 \mathrm{~m}^{2}$ dir. Yeni tasarımda ise $23,36 \mathrm{~m}^{2} \mathrm{dir}$.

12- ÇEŞITITLI DEMIR İMALAT: Her iki hazne kapı ve pencere boyutları aynı olduğundan ikisinde de miktar yaklaşık 150 kg'dır.

13-SERAMIK DÖŞEME: Eski biriktirme haznesi tabanı için 11,24 $\mathrm{m}^{2}$ seramik döşeme gerekirken, yenisi için $4,20 \mathrm{~m}^{2}$ yeterli olmaktadır.

14-NAKLIYELER(YÜKLEME-BOŞALTMA VE İSTIF DÂHIL):Eski hazne için nakliyeye esas malzemelerin tutarı 864,23 TL'dir. Yeni hazne için 195,72 TL'dir. 668,51 TL azalma olmaktadır [10].

4.3 Öneriler

Bundan sonra yapılacak su biriktirme haznelerinin tasarımı yapılırken; tabanı, köpük oluşumunun, çamur birikmesinin ve koku oluşumunun olmaması için açılı (konik) yapılabilir [10].

\section{Kaynakça}

[1] Anadolu'da Suyun İzi, Hülagu Kozanoğlu, Anadolu'da Su Medeniyeti Dizisi: 4 Yayın No: 7 Aski Genel Müdürlüğü Yayınları Ankara, 2013

[2] Karpuzcu, M., Su Temini ve Çevre Sağlığı, Kubbealtı Neşriyatı, İstanbul, 2005

[3] Yaşlak, Y.Y., Tek ve Çok Gözlü Betonarme Dikdörtgen Su Depolarının İncelenmesi, Yüksek Lisans Tezi, Balıkesir, 2012

[4] Çelebioğlu, M.F., Silindirik Su Deposu Tasarımı, Yüksek Lisans Tezi, İstanbul, 2004

[5] Su Getirme Etüt ve Proje Bilgisi, Başbakanlık Köy Hizmetleri Genel Müdürlüğü Etüt ve Proje Dairesi Başkanlığı, Ankara, 2000.

[6] K.H İçmesuyu Ön Proje (ETÜT) ve Proje Teknik Şartnamesi, Tarım ve Köyişleri Bakanlı̆̆ Köy Hizmetleri Genel Müdürlüğü Etüt ve Proje Dairesi Başkanlığı, Ankara, 2004.

[7] https://www.impo.com.tr

[8] Çorum İl Özel İdaresi Su ve Kanal Hizmetleri Müdürlüğü Derin Dalgıç Elektromotopomp Grubu ve Gerekli Diğer Malzemeler Özel Teknik Şartnamesi

[9] Ay, M., Su Kalitesi Parametrelerinin Yapay Zeka Yöntemleri İle Değerlendirilmesi, Doktora Tezi, Kayseri, 2014

[10] Ateş, O., Betonarme Su Biriktirme Haznelerinin Tasarımı, Yüksek Lisans Tezi, Yozgat, 2019 